\title{
Manic Symptoms Due to Methylphenidate Use in an Adolescent with Traumatic Brain Injury
}

\author{
Ozalp Ekinci ${ }^{1}$, Meltem Çobanoğullari Direk ${ }^{2}$, Nuran Ekinci ${ }^{1}$, Cetin Okuyaz $^{2}$ \\ 'Department of Child and Adolescent Psychiatry, ${ }^{2}$ Department of Pediatric Neurology, Mersin University Medical Faculty, Mersin, Turkey
}

\begin{abstract}
Almost one-fifth of children who sustain a traumatic brain injury (TBI) are under the risk of attention problems after injury. The efficacy and tolerability of methylphenidate (MPH) in children with a history of TBI have not been completely identified. In this case report, MPH-induced manic symptoms in an adolescent with TBI will be summarized. A male patient aged 17 years was admitted with the complaints of attention difficulties on schoolwork and forgetfullness which became evident after TBI. Long-acting $\mathrm{MPH}$ was administered with the dose of $18 \mathrm{mg} /$ day for attention problems. After one week, patient presented with the complaints of talking to himself, delusional thoughts, irritability and sleeplessness. This case highlights the fact that therapeutic dose of $\mathrm{MPH}$ may cause mania-like symptoms in children with TBI. Close monitarization and slow dose titration are crucial when considering MPH in children with TBI.
\end{abstract}

KEY WORDS: Brain injuries; Adolescent; Methylphenidate; Bipolar disorder.

\section{INTRODUCTION}

Traumatic brain injury (TBI) is a leading cause of morbidity and mortality in children, resulting in numerous physical, behavioral and cognitive deficits. ${ }^{1)}$ Cognitive deficits may involve problems with attention, memory and executive functions that worsen with increasing TBI severity. ${ }^{2-4)}$ Attention deficit hyperactivity disorder (ADHD) that develops after injury without evidence of preinjury ADHD is often referred to as secondary ADHD. ${ }^{5}$

Methylphenidate (MPH), a well-accepted treatment for ADHD, may be associated with behavioral adverse effects. ${ }^{6}$ ) Amongst these reactions, psychotic symptoms are the most terrifiying ones for families. Although firstly reported in the early 1970s, the terminology of psychotic symptoms due to MPH use has not been well described. The first report of stimulant-induced psychosis and/or mania symptoms in children included three cases and used the definition of "methylphenidate hallucinosis'. ') In these cases, hallucinations were the prominent presenting sym-

Received: September 21, 2015 / Revised: November 3, 2015

Accepted: December 7, 2015

Address for correspondence: Ozalp Ekinci

Department of Child and Adolescent Psychiatry, Mersin University

School of Medicine, No:31, Çiftlikköy, Vali Şenol Engin Cd., 33110

Mersin, Turkey

Tel: +90-506-611-15-00, Fax: +90-3242410092

E-mail: ozalpekinci@yahoo.com ptoms. In later reports, the term 'toxicosis' has been used to distinguish transient psychotic symptoms associated with stimulant use. ${ }^{8)}$ Toxicosis term specifically indicates that the psychotic-like or mania-like symptoms resolve following discontinuation of stimulant. When the adverse reaction symptoms continue or recur after discontinuation, a rediagnosis of bipolar disorder or schizophrenia may be considered. ${ }^{8)}$

The efficacy and tolerability of stimulants in children with a history of TBI have not been completely identified. In this case report, the emergence of manic symptoms with MPH use in an adolescent with TBI will be summarized. Informed consent was obtained from the patient's parents.

\section{CASE}

A male patient aged 17 years was admitted to the child and adolescent psychiatry clinic with the complaints of attention difficulties on schoolwork and forgetfullness. Patient's medical history revealed that he had a car accident 3 months ago which included a TBI. Upon admission to emergency room, his Glasgow Coma Scale score was $6 / 15$. At the time of the accident, his neurologic assessment was marked with upper and lower muscular weakness, memory deficits and frank mutism. This clinic picture resolved in 2 months; however, he has been speaking slowly since then. Before the accident, he was reported to

(a) This is an Open-Access article distributed under the terms of the Creative Commons Attribution Non-Commercial License (http://creativecommons.org/licenses/by-nc/4.0) which permits unrestricted non-commercial use, distribution, and reproduction in any medium, provided the original work is properly cited. 
have a succesfull academic life in both elementary and secondary school. He never had attention problems, hyperactivity or impulsivity. Prior psychiatric history of the patient did not reveal any psychiatric disorder diagnosis. There was no known history of psychiatric disorders in both parents and extended family members. After the accident, he had difficulty on sustaining attention on school work and forgetfulness on daily duties. He described himself as "I study hard and try to do my best but I am far from my previous academic performance. I can't focus, can't sustain my attention and I do simple mistakes". Deficits in cerebellar tests, slow speech and difficulty at walking on hills were evident in his neuorologic examination. His magnetic resonance imaging (MRI), which was performed 10 days after the injury, revealed postinjury findings on the right frontal lob, lef temporal lobe and corpus callosum (Fig. 1). Sleep and awake electroencephalography (EEG) of the patient was also obtained on the 7th day after injury. Sleep EEG showed 4-6 Hz theta waves mixed with $\mathrm{V}$ waves and sleep spindles. Awake EEG showed 8-9 Hz alpha waves in posterior regions. There were no cerebral assymetry, focal slowing or epileptiform discharges.

A diagnosis of major neurocognitive disorder due to TBI was made and osmotic release oral system (OROS)
MPH was administered with the dose of $18 \mathrm{mg} /$ day for attention problems. After one week, patient was admitted to the clinic with the complaints of talking to himself, delusional thoughts, irritability and sleeplessness. He was reported to speak everyone that he and his father were prophets. He was reported to be more talkative than usual especially in social situations. His psychiatric interview revealed elevated mood, incongruent affect and delusional thoughts about his mission to save the world. The patient's Young Mania Rating Scale (YMRS) score was 29. His general pediatric and neurologic evaluation did not reveal any additional findings. The Naranjo adverse drug reaction probability scale score was 8 . With the suspect of a medication induced adverse reaction, MPH was discontinued and all of the symptoms resolved in 3 days. Three days after the discontinuation of MPH, YMRS score decreased to 4 .

\section{DISCUSSION}

Almost one fifth of children who sustain a TBI are under the risk of attention problems after injury. ${ }^{9)}$ Children with severe TBI are shown to have a greater risk for developing postinjury attention problems. ${ }^{10)}$ The consequences
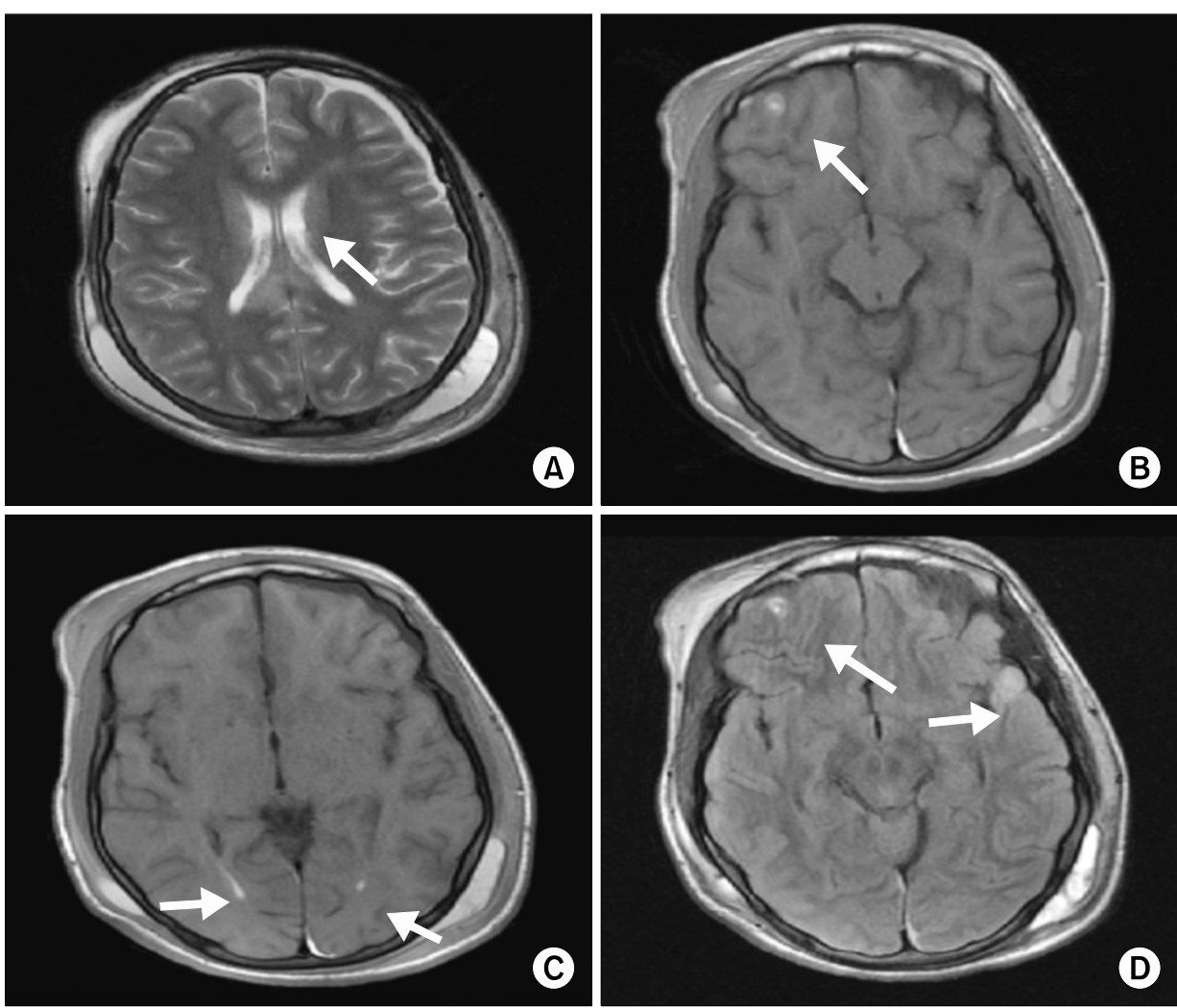

Fig. 1. (A) On the T2-weighted axial image, increased focal signal intensity in corpus callosum. (B) On the Tl-weighted axial image, hemorrhage and contusion in right frontal lobe grey matter. (C) On the T1-weighted axial image, minimal intraventricular hemorrhage. (D) On the fluid-attenuated inversion recovery (FLAIR) examination axial image, contusion and related increase in focal signaling in the right frontal and left temporal lobes grey matter. 
of attention problems may extend beyond school functioning and can have negative impacts on a child's social relationships, emotional well-being, self esteem and quality of life. ${ }^{11)}$

Despite the high burden of attention problems in children and adolescents after TBI, only a limited number of controlled studies, all with small sample size and short duration, have been conducted to date. In an early study by Williams et al. ${ }^{12)}$ no signifficant effect of MPH was reported in 10 children with mild-to-severe head trauma. Mahalick et al ${ }^{13)}$ studied 14 children with TBIs of varying severity and MPH treatment resulted in significantly greater scores on the study measures of attention when compared with placebo. A chart review on 10 children with TBI has also shown positive findings on attention and behavior. ${ }^{14)}$ A recent placebo controlled study, in which only five children with TBI have completed the study procedures, reported a small but significant effect on attention and hyperactivity with psychostimulants. ${ }^{1)}$ Of note, none of the mentioned studies focused on the possible adverse effects of MPH and treatment associated mania or psychosis was not reported.

The risk of stimulant-induced psychosis and/or mania symptoms in children as estimated as 1 in $400 .^{8)}$ In a significant proportion of cases, toxicosis symptoms develop at the theraupatic doses of stimulants. ${ }^{15)}$ Presenting symptoms usually emerge shorty after the start of the treatment or with a dose increase. In the great majority of such reports, behavioral symptoms resolve within a week after discontinuation. ${ }^{16)}$ In accordance with the literature, manic symptoms started within the first week of MPH treatment, and rapidly subsided with discontinuation in our case. It has been shown that stimulant induced toxicosis symptoms are highly similar to those of bipolar disorder or schizophrenia. ${ }^{8)}$ Symptoms may include euphoria, grandiosity, paranoid delusions, confusion and auditory hallucinations. ${ }^{8,16)}$ Bizarre behaviors, hallucinations involving visual and/or tactile sensations of insects, snakes, or worms were also reported, especially in younger children. ${ }^{17)}$ Our case also presented with grandiose delusions with religious content and socialy disinhibited behaviors which are commonly reported in manic episodes. In the differential diagnosis, bipolar disorder manic episode might be a possibility. However, the short duration of symptoms and the direct relationship with MPH use do not fit the Diagnostic and Statistical Manual of Mental Disorders 5th edition (DSM-V) criteria. $^{18)}$ Moroever, MPH-induced mania symptoms must be considered as a different clinical entity than the highly hereditery bipolar disorder. Acute onset of clinical picture, absence of mood symptoms in the prior psychiatric history and the lack of the family history in the present case are against a bipolar disorder diagnosis. ${ }^{17)}$ In light of the available research and the suggested terminology, toxicosis term appears to be the best description of the case.

Although not completely identified, the emergence of psychotic symptoms may be related with the mechanism of action of MPH. MPH mainly works via the reuptake inhibition of dopamine, and less prominently noradrenaline, in the striatal regions. Effects on selected frontal and temporal regions were also observed with MPH use. ${ }^{19)}$ Increased dopaminergic and/or noraderengic transmission with MPH, especially in higher doses, may be associated with psychotic/manic symptoms. ${ }^{8)}$ Although stimulantinduced toxicosis appears to be an idiosyncratic reaction, some risk factors have been proposed. The use of high doses, premorbid ADHD symptoms and mental retardation were suggested to be related with an increased risk. $^{20)}$

In the present case, the disrupted brain regions, as shown by the MRI findings, might give rise to a vulnerability for this behavioral adverse reaction. Right frontal, left temporal regions and corpus callosum, which were injuried in our case, are among the shown regions for the neurobiology of bipolar disorder in children and adolescents. ${ }^{21,22)}$ Deficits in executive functions, visual-motor responses and working memory were reported in children with traumatic lesions on corpus callosum. ${ }^{23)}$ The previous literature on mania symptoms after TBI is limited. Some studies have shown that multifocal lesions, mainly in temporal poles, are associated with mania. ${ }^{24)}$ Both left and right temporal lesions were found to be linked with mania symptoms. ${ }^{25,26)}$ A previous review on 66 adult TBI patients have shown the incidence of mania as $9 \%$ within 12 months of follow-up. ${ }^{27)}$ There is evidence that severe TBI and male gender are associated with an increased risk of mania. ${ }^{28,29)}$ The relationship between age and mania has not been specifically documented, however, younger age has been found as a risk factor for psychiatric disorders after TBI ${ }^{30,31)}$ In our case, diffuse disruptions in fronto-temporal grey matter might have resulted with an increased vulnerability to manic symptoms. Since these vulnerable regions are also among the shown target regions of MPH, an additive effect of MPH might have occured. In other words, MPH use might have led to either irreguler or overt activity in the brain regions which were already disrupted with the head trauma. Eventually, the additive effects of head trauma and MPH use might have resulted in the 
emergence of manic symptoms in our case, which did not have any premorbid psychiatric history.

This case highlights the fact that therapeutic dose of MPH may cause mania-like symptoms in children with TBI. Close monitarization and slow dose titration are crucial when considering MPH in children with TBI.

\section{REFERENCES}

1. Nikles CJ, McKinlay L, Mitchell GK, Carmont SA, Senior $\mathrm{HE}$, Waugh MC, et al. Aggregated n-of-1 trials of central nervous system stimulants versus placebo for paediatric traumatic brain injury--a pilot study. Trials 2014;15:54.

2. Catroppa C, Anderson V. Traumatic brain injury in childhood: rehabilitation considerations. Dev Neurorehabil 2009; 12:53-61.

3. Beauchamp M, Catroppa C, Godfrey C, Morse S, Rosenfeld $\mathrm{JV}$, Anderson V. Selective changes in executive functioning ten years after severe childhood traumatic brain injury. Dev Neuropsychol 2011;36:578-595.

4. Taylor HG, Swartwout MD, Yeates KO, Walz NC, Stancin T, Wade SL. Traumatic brain injury in young children: postacute effects on cognitive and school readiness skills. J Int Neuropsychol Soc 2008;14:734-745.

5. Gerring JP, Brady KD, Chen A, Vasa R, Grados M, Bandeen-Roche KJ, et al. Premorbid prevalence of $A D H D$ and development of secondary ADHD after closed head injury. J Am Acad Child Adolesc Psychiatry 1998;37:647-654.

6. Kim BN, Kim YN, Cheong US, Kim JW, Hwang JW, Shin MS, et al; Korean OROS-MPH Study Group. Switching from Methylphenidate-Immediate Release (MPH-IR) to Methylphenidate-OROS (OROS-MPH): A multi-center, open-label study in Korea. Clin Psychopharmacol Neurosci 2011;9:29-35.

7. Lucas AR, Weiss M. Methylphenidate hallucinosis. JAMA 1971;217:1079-1081.

8. Ross RG. Psychotic and manic-like symptoms during stimulant treatment of attention deficit hyperactivity disorder. Am J Psychiatry 2006;163:1149-1152.

9. Backeljauw B, Kurowski BG. Interventions for attention problems after pediatric traumatic brain injury: what is the evidence? PM R 2014;6:814-824.

10. Max JE, Lansing AE, Koele SL, Castillo CS, Bokura H, Schachar R, et al. Attention deficit hyperactivity disorder in children and adolescents following traumatic brain injury. Dev Neuropsychol 2004;25:159-177.

11. Wehmeier PM, Schacht A, Barkley RA. Social and emotional impairment in children and adolescents with $A D H D$ and the impact on quality of life. J Adolesc Health 2010; 46:209-217.

12. Williams SE, Ris MD, Ayyangar R, Schefft BK, Berch D. Recovery in pediatric brain injury: is psychostimulant medication beneficial? J Head Trauma Rehabil 1998;13:73-81.

13. Mahalick DM, Carmel PW, Greenberg JP, Molofsky W, Brown JA, Heary RF, et al. Psychopharmacologic treatment of acquired attention disorders in children with brain injury. Pediatr Neurosurg 1998;29:121-126.

14. Hornyak JE, Nelson VS, Hurvitz EA. The use of methyl- phenidate in paediatric traumatic brain injury. Pediatr Rehabil 1997;1:15-17.

15. Hellander M. Medication-induced mania: ethical issues and the need for more research. $J$ Child Adolesc Psychopharmacol 2003;13:199.

16. Shibib S, Chalhoub N. Stimulant induced psychosis. Child Adolesc Ment Health 2009;14:20-23.

17. Mosholder AD, Gelperin K, Hammad TA, Phelan K, Johann-Liang R. Hallucinations and other psychotic symptoms associated with the use of attention-deficit/hyperactivity disorder drugs in children. Pediatrics 2009;123:611-616.

18. American Psychiatric Association. Diagnostic and statistical manual of mental disorders. 5th ed. Washington, DC: American Psychiatric Association;2013.

19. Czerniak SM, Sikoglu EM, King JA, Kennedy DN, Mick E, Frazier J, et al. Areas of the brain modulated by single-dose methylphenidate treatment in youth with $A D H D$ during task-based fMRI: a systematic review. Harv Rev Psychiatry 2013;21:151-162.

20. Chakraborty K, Grover S. Methylphenidate-induced manialike symptoms. Indian J Pharmacol 2011;43:80-81.

21. Demeter CA, Townsend LD, Wilson M, Findling RL. Current research in child and adolescent bipolar disorder. Dialogues Clin Neurosci 2008;10:215-228.

22. Barnea-Goraly N, Chang KD, Karchemskiy A, Howe ME, Reiss AL. Limbic and corpus callosum aberrations in adolescents with bipolar disorder: a tract-based spatial statistics analysis. Biol Psychiatry 2009;66:238-244.

23. Treble A, Hasan KM, Iftikhar A, Stuebing KK, Kramer LA, Cox CS Jr, et al. Working memory and corpus callosum microstructural integrity after pediatric traumatic brain injury: a diffusion tensor tractography study. J Neurotrauma 2013;30:1609-1619.

24. Schwarzbold M, Diaz A, Martins ET, Rufino A, Amante LN, Thais ME, et al. Psychiatric disorders and traumatic brain injury. Neuropsychiatr Dis Treat 2008;4:797-816.

25. Murai T, Fujimoto S. Rapid cycling bipolar disorder after left temporal polar damage. Brain Inj 2003;17:355-358.

26. Robinson RG, Boston JD, Starkstein SE, Price TR. Comparison of mania and depression after brain injury: causal factors. Am J Psychiatry 1988;145:172-178.

27. Jorge RE, Robinson RG, Starkstein SE, Arndt SV, Forrester AW, Geisler FH. Secondary mania following traumatic brain injury. Am J Psychiatry 1993;150:916-921.

28. Shukla S, Cook BL, Mukherjee S, Godwin C, Miller MG. Mania following head trauma. Am J Psychiatry 1987; 144:93-96.

29. van Reekum R, Bolago I, Finlayson MA, Garner S, Links PS. Psychiatric disorders after traumatic brain injury. Brain Inj 1996;10:319-327.

30. Deb S, Lyons I, Koutzoukis C, Ali I, McCarthy G. Rate of psychiatric illness 1 year after traumatic brain injury. Am J Psychiatry 1999;156:374-378.

31. Schachar RJ, Park LS, Dennis M. Mental health implications of traumatic brain injury (TBI) in children and youth. J Can Acad Child Adolesc Psychiatry 2015;24: 100-108. 